Review article

\title{
SELECTING THE BEST TREATMENT OPTION FOR A DOG WITH CUSH ING `S SYNDROME
}

\author{
GALAC Sara \\ Dept. of Clinical Sciences of Companion Animals, Faculty of Veterinary Medicine, Utrecht University, \\ Utrecht, The Netherlands
}

(Received $28^{\text {th }}$ January; Accepted $17^{\text {th }}$ February 2015)

\begin{abstract}
Spontaneous hypercortisolism or Cushing's syndrome is a common endocrinopathy in dogs. Pituitary-dependent and adrenal-dependent hypercortisolism each require specific treatment and diagnostic imaging is very helpful in choosing the treatment that is appropriate. The aims and expectations of the treatment need to be established beforehand and discussed with the owner to avoid unexpected disappointments. The clinical signs of pituitary-dependent hypercortisolism caused by a pituitary microadenoma can be managed with the adrenocorticostatic drug trilostane, but the drug will not affect the pituitary tumor. Hypophysectomy is therefore preferred in those dogs that have an enlarged pituitary but are in good clinical condition and have a long life-expectancy. Inoperable pituitary tumors can be treated by radiotherapy. The best treatment in dogs with cortisol-secreting adrenocortical tumors is adrenalectomy. If surgery is not possible, because of vascular invasion or metastatic spread, mitotane is recommended. Treatment with trilostane can be considered but is only palliative: it does not affect the adrenocortical tumor.
\end{abstract}

Key words: hypophysectomy, adrenalectomy, trilostane, mitotane, dogs

\section{INTRODUCTION}

Spontaneous hypercortisolism or Cushing's syndrome is characterized by physical and biochemical changes resulting from chronic exposure to elevated concentrations of circulating glucocorticoid. About $80-85 \%$ of cases of hypercortisolism in dogs are adrenocorticotropin (ACTH)-dependent, most often the result of excessive secretion of ACTH by a pituitary corticotroph adenoma. In the remaining cases hypercortisolism is ACTH-independent, the result of excessive secretion of glucocorticoids by an adrenocortical tumor (AT) [1]. The ectopic ACTH secretion syndrome and ACTHindependent or primary bilateral adrenal hyperplasia are both rare in dogs $[2,3]$.

The pituitary lesions producing excess ACTH range from small nests of hyperplastic corticotrophs (or melanotrophs) to micro- or macroadenomas. Pituitary macroadenomas can eventually invade surrounding tissues such as the cavernous sinus,

Corresponding author: e-mail: S.Galac@uu.nl 
dura mater, brain, and rarely the sphenoid bone. These are called invasive adenomas, to distinguish them from pituitary tumors with extracranial metastasis, which are a rare in dogs [4].

Cortisol-secreting ATs can be divided into adenomas and carcinomas, but histological differentiation is not always straightforward. Histological markers of adrenocortical carcinoma include vascular invasion, intracapsular growth, and atypical nuclei [5]. However, the most reliable indicator of malignancy at present is metastasis.

\section{Establishing the diagnosis of hypercortisolism}

Cushing's syndrome is a disease of middle-aged and older dogs. There is no gender predilection. It occurs in all breeds, with a slight predilection for small breeds such as the Dachshund and the Miniature Poodle. Many of the clinical signs can be related to the biochemical effects of glucocorticoids, namely, gluconeogenesis and lipogenesis at the expense of protein (Figure 1). In dogs, the cardinal physical features are centripetal

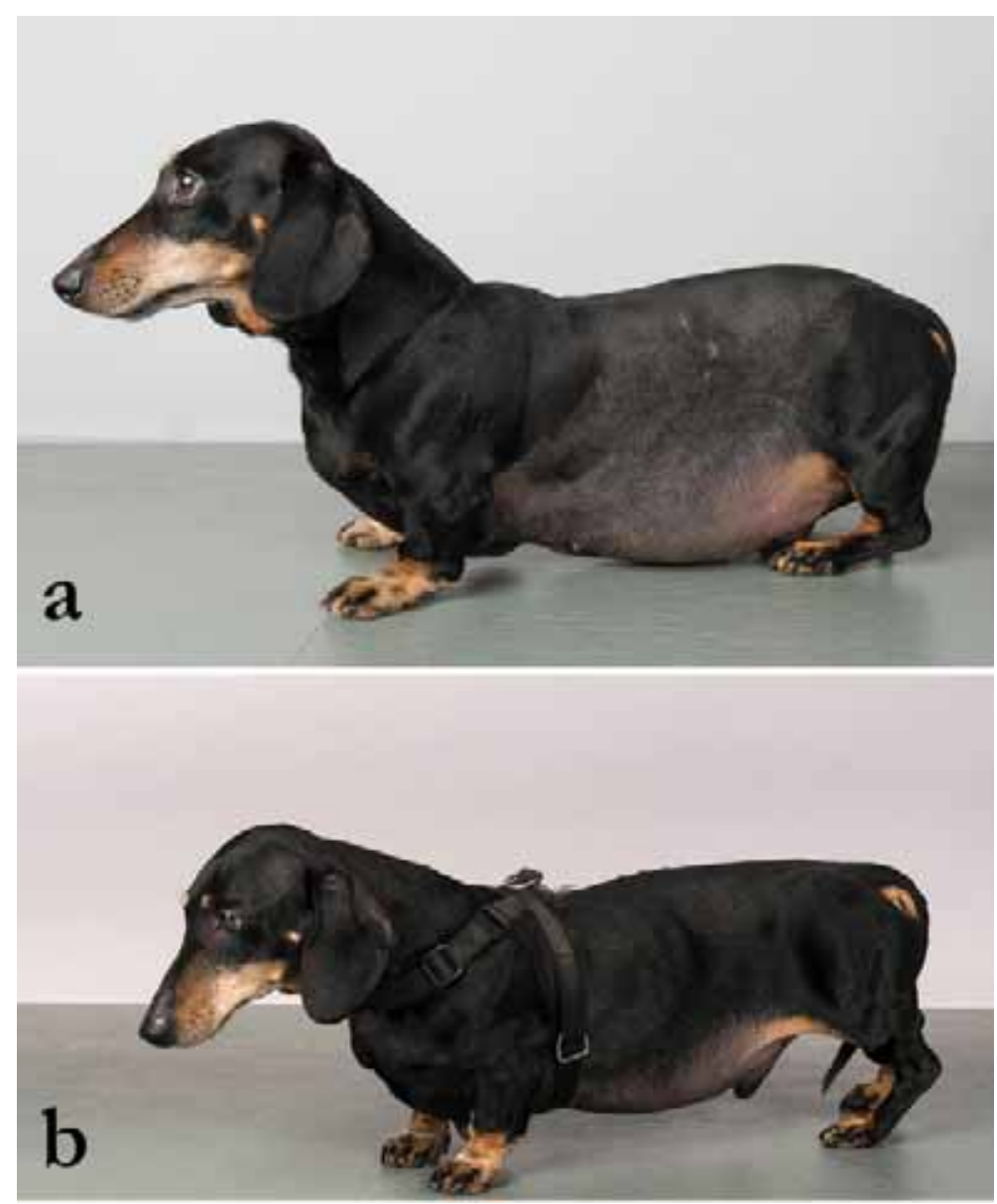

Figure 1 A dog with hyperocrtiosolism at the time of diagnosis (a) and during trilostane therapy (b) 
obesity, alopecia, and atrophy of muscles and skin. Abdominal palpation may reveal hepatomegaly [1]. Polyuria and polyphagia are also prominent features. The polyuria is known to be due to impaired osmoregulation of vasopressin release and interference by the glucocorticoid excess with the action of vasopressin in the kidney.

The biochemical diagnosis of hypercortisolism depends on the demonstration of two characteristics: increased production of cortisol and decreased sensitivity to glucocorticoid feedback [6]. The diagnostic approach has been reviewed recently in a consensus statement by leading veterinary endocrinologists [7]. It has been agreed that in dogs with clinical signs of hypercortisolism, the diagnosis should be confirmed by tests of cortisol secretion and integrity of the feedback system. The low-dose dexamethasone suppression test (LDDST) is the most recommended test for this purpose. Measurement of plasma cortisol at 4 and 8 hours after dexamethasone administration is recommended to differentiate between pituitary- and adrenaldependent hypercortisolism [8]. Measurement of the urinary corticoid to creatinine ratio is a convenient test for hypercortisolism, if performed at home to avoid the influence of stress [9]. Urinary corticoid excretion represents an integrated measure of corticoid production over an interval (usually one night), smoothing the effects of short-term fluctuations in plasma cortisol concentration. As it can be easily combined with the HDDST, the two forms of hypercortisolism can be differentiated in one test, but its reliability depends on the availability of a trustworthy assay [10]. The ACTH stimulation test, which has been used in the diagnosis of spontaneous hypercortisolism in dogs for quite some time, is no longer recommended [7]. In principle it is a test of adrenocortical reserve capacity, used to diagnose primary and secondary adrenocortical insufficiency. It can thus be used to diagnose iatrogenic hypercortisolism, which via feedback suppression results in secondary adrenocortical insufficiency [11]. In addition, this test is now often used to monitor treatment with trilostane [12]. Measurement of plasma ACTH concentration is useful to differentiate between the adrenal- and pituitarydependent forms of hypercortisolism, but not for other diagnostic purposes [6]. Plasma ACTH concentration is expected to be low or undetectable in adrenal hypercortisolism but in cases of pituitary tumor it may be elevated or within the normal range, because of the pulsatile secretion pattern of ACTH.

\section{Diagnostic imaging of the pituitary and adrenal glands}

Diagnostic imaging of the pituitary and adrenals is of great value in determining the best treatment and for objectively evaluating the prognosis. The pituitary can be visualized by computed tomography (CT, Figure 2) or nuclear magnetic resonance imaging (MRI) $[13,14]$. In healthy dogs, the pituitary gland is 6 to $10 \mathrm{~mm}$ in length, 5 to $9 \mathrm{~mm}$ in width, and 4 to $6 \mathrm{~mm}$ in height [15]. The size of the pituitary can be evaluated by means of the ratio between its height and the area of the brain $(\mathrm{P} / \mathrm{B}$ ratio), measured on a CT image through the center of the pituitary: a P/B ratio greater than 0.31 indicates pituitary enlargement $[16,17]$. 

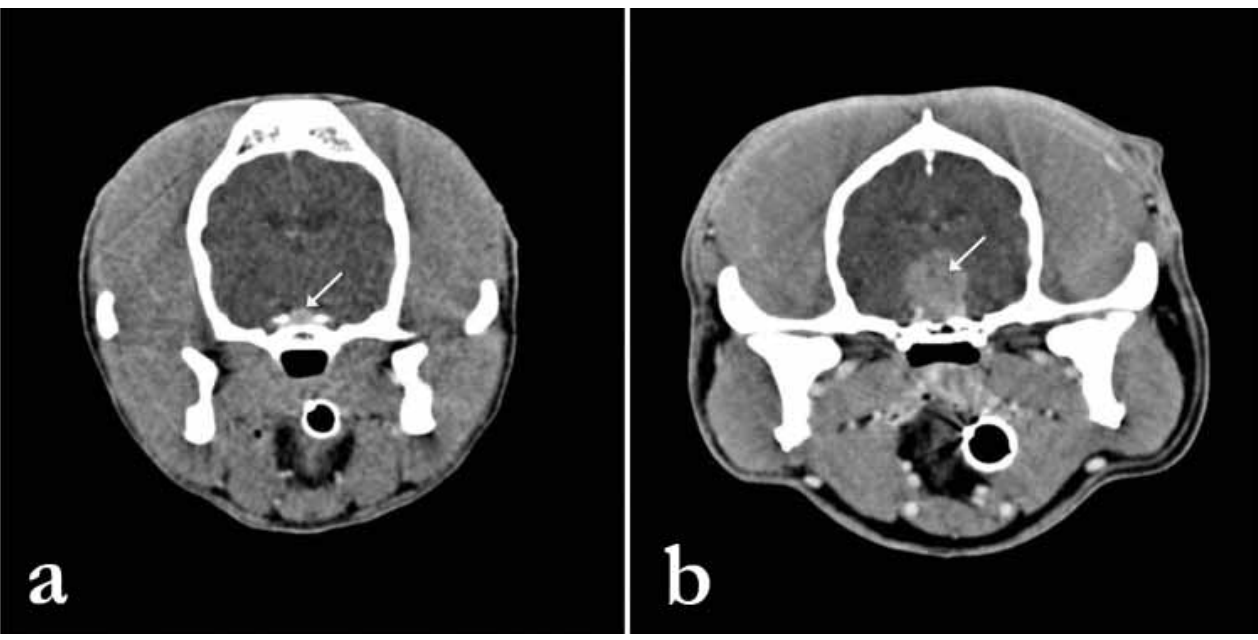

Figure 2. Mildly (a) and severely (b) enlarged pituitary gland in two dogs with pituitarydependent hypercortisolism visualized by computer tomography. An arrow pints to the pituitary gland

Macroadenomas of the pituitary are easily detected on contrast-enhanced CT images because they alter the size and shape of the gland, but a normal appearance does not exclude the possible presence of a microadenoma. The classification of pituitary adenomas in humans as microadenomas $(0.10 \mathrm{~mm})$ and macroadenomas $(10 \mathrm{~mm})$ is not useful in dogs, where adenomas between 6 and $10 \mathrm{~mm}$ in height enlarge the gland and therefore cannot be classified as microadenomas. Direct visualization of the pituitary adenoma is only possible when the imaging characteristics of the adenoma are different from those of the surrounding normal pituitary tissue. The enhancement pattern of the neurohypophysis during dynamic contrast enhanced CT has been called the 'pituitary flush'. The displacement, distortion, or disappearance of the pituitary 'flush sign' in the early phase of dynamic CT examinations can be used to identify both micro- and macroadenomas in dogs [18].

The adrenal glands can also be visualized by CT [19-21], but ultrasonography is less expensive, requires less time, and does not require anesthesia, and so it is often used first (Figure 3) [22,23]. Attention has been given to the symmetry, size, shape, and echogenicity of adrenal glands. Bilateral enlargement of the adrenal glands is expected in PDH, while a cortisol-secreting AT usually presents as a unilateral adrenal mass with atrophy of the contralateral adrenal. Determining the size of the adrenals has been controversial. An adrenal diameter greater than $7 \mathrm{~mm}$ has been reported to signify hyperplasia, with a sensitivity of $77 \%$ and specificity of $80 \%$ [23]. Recently, Choi and coauthors [24] reported that in dogs weighing less than $10 \mathrm{~kg}$ a diameter greater than $6 \mathrm{~mm}$ indicates $\mathrm{PDH}$, with a sensitivity of $75 \%$ and a specificity $94 \%$. The structure of the adrenal may be more important than its size. In hyperplastic adrenal glands the normal shape is preserved and the sonographic appearance is homogeneous [25]. Contrast-enhanced ultrasonography is a relatively new approach in evaluating 

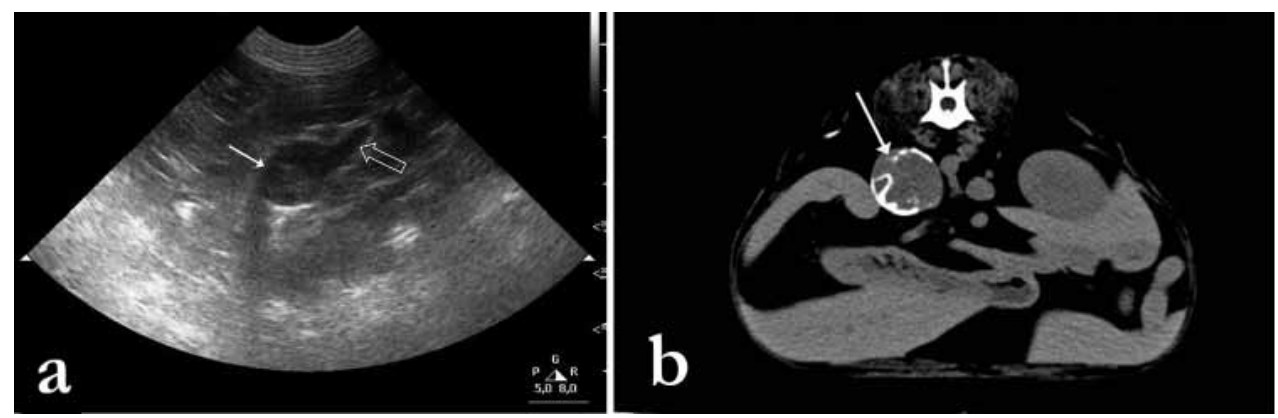

Figure 3. Cortisol-secreting adrenocortical tumor visualized by ultrasonography (a) and computer tomography (b). A nodular change in the cranial pool of the adrenal (arrow) and atrophic caudal part of the adrenal gland (hole arrow) are noted. Computer tomography demonstrated a heterogenous structure of the adrenocortical tumor

adrenal glands [26-28]. During this procedure, the contrast agent is administered IV and time-intensity curves are generated for the adrenal cortex, adrenal medulla, and ipsilateral renal artery of both adrenal glands. Contrast-enhanced ultrasonography is able to detect vascular changes induced by hypercortisolism. In normal dogs, contrast enhancement distribution in the adrenals is homogeneous and in the washout phase there is a gradual and homogeneous decrease in enhancement [26]. In dogs with PDH, there is a rapid, chaotic, and simultaneous contrast enhancement in both the cortex and medulla [28]. In addition, the peak contrast intensity in both the cortex and the medulla was twice as high in dogs with $\mathrm{PDH}$ compared with that of healthy controls. Further studies are needed to determine whether reference ranges for clinically normal dogs and dogs with PDH can be determined and applied in clinical settings. This approach may be promising in the diagnosis of bilateral adrenocortical tumor as well as in differentiating between tumor and adrenocortical hyperplasia [27]. Especially differentiation between bilateral cortisol-secreting ATs and hyperplastic adrenals is challenging [29,30]. Bilateral ATs are not very common and it is a heterogeneous echographic appearance, reflecting necrosis and hemorrhage in the adrenals, which may suggest tumor rather than hyperplasia. Asymmetry of the adrenal glands is a typical ultrasonographic finding with a unilateral cortisol-secreting AT. In addition to the size and structure of an AT, its expansion into the blood vessels and possible metastasis to the liver are also evaluated. If nodular structures are revealed in the liver, ultrasound-guided needle aspiration biopsy can be performed. Radiographs or a CT scan of the thorax should be made to determine whether there are metastases in the lungs.

\section{TREATMENT}

The goal of treatment of hypercortisolism is to eliminate the cause. Depending on the etiology, this may be achieved by transsphenoidal hypophysectomy, adrenalectomy, radiotherapy, or medical treatment with trilostane or o,p'-DDD (mitotane). 


\section{Pituitary-dependent hypercortisolism}

\section{Surgic al treatment}

Ideally, the treatment of canine PDH should be removal of the ACTH-producing adenoma [1]. Otherwise, the tumor may continue to grow and eventually lead to neurological signs associated with an intracranial mass. However, hypophysectomy requires the joint efforts of a neurosurgeon, an endocrinologist, a radiologist, and an intensivist and it is therefore not available in most cases [31]. A CT scan of the pituitary is a surgical prerequisite for localization of the gland in relation to the anatomical landmarks and for assessment of pituitary size [13]. In the hands of a skilled neurosurgeon, microsurgical transsphenoidal hypophysectomy has proved to be a safe and effective treatment for Cushing's disease in dogs [32,33]. Following hypophysectomy, hormone replacement therapy consists of lifelong administration of cortisone acetate and thyroxine. Desmopressin, a synthetic vasopressin analogue, is needed temporarily because in dogs removal of the pituitary adenoma by hypophysectomy also removes the pars nervosa, via which the antidiuretic hormone arginine vasopressin, secreted by the hypothalamic paraventricular and supraoptic nuclei, reaches the systemic circulation [34]. Hypophysectomy thus results in transient central diabetes insipidus (CDI) for up to 2 months, after which desmopressin can be gradually withdrawn. However, in about $10 \%$ of cases, the CDI remains permanently [33].

The major complications of hypophysectomy are postoperative mortality, hypernatremia due to acute vasopressin deficiency, prolonged central diabetes insipidus, keratoconjunctivitis sicca (KCS), and residual or recurrent hypercortisolism [34]. Postoperative mortality and severe hypernatremia have been reduced over the years as a result of better intensive care facilities and the learning curve of the critical care specialist [35]. Frequent sodium measurements in the postoperative period and adjustments in fluid therapy are key to prevent life-threatening changes in osmolality. Patient selection has also contributed to the decrease in postoperative mortality. Dogs in poor clinical condition due to hypercortisolism are now treated with the adrenocorticostatic drug trilostane until their clinical condition improves sufficiently for surgery. KCS can be a severe complication after transsphenoidal hypophysectomy if left untreated. Routine postoperative use of the Schirmer tear test (STT) and immediate ophthalmologic treatment prevent the development of lesions in the cornea. There is no correlation between pituitary size and development of KCS. Its development after hypophysectomy has been ascribed to direct (traumatic) or indirect (ischemic) neuropraxia of the major petrosal nerves, resulting in a secretomotoric deficit in the lacrimal glands, but this has not yet been proved and the pathogenesis remains uncertain. Most dogs recover completely but in few tear production remains low for life. The ST'T should be performed on the first day after hypophysectomy, for early detection and treatment prevents the development of severe KCS. 
The 10-year follow-up findings after hypophysectomy in 150 dogs with PDH showed that it is effective, especially in the long term, with remission for up to seven years [32]. With increasing pituitary size the survival and disease-free periods decrease and the incidence of central diabetes insipidus increases. The recurrence rate of $25 \%$ compares favorably with that after nonselective adrenocortical destruction with mitotane [36]. Hence transsphenoidal hypophysectomy can be expected to have the best outcome as the primary treatment in dogs with nonenlarged or only moderately enlarged pituitaries [33]. The recurrence rate increases with longer follow-up intervals after initially successful surgery. This may be because normal corticotrophs present in the sella turcica after surgery tend to remain functional (much more so than the other cell types) and maintain normocorticism, while residual adenoma cells are insensitive to feedback control and eventually cause recurrence of hypercortisolism.

In dogs with larger pituitary tumors and tumor extension rostrally or caudally over the dorsum sellae, transsphenoidal debulking surgery may be only palliative and radiotherapy might be preferred.

\section{Medical treatment}

Selective [37] or nonselective [36] destruction of the adrenal cortex with $\mathbf{0 , p}$ 'DDD (mitotane) has long been the medical treatment of choice for PDH in dogs. Selective treatment aim at selective destruction of the zona fasciculata $(\mathrm{ZF})$ and zona reticularis (ZR), sparing the zona glomerulosa (ZG). However, in 5-6\% of dogs in which this is attempted, the ZG is also destroyed to such an extent that iatrogenic hypoadrenocorticism develops. On the other hand, in more than half of the cases in which selective destruction is the aim, there are one or more relapses of hypercortisolism during treatment. In order to avoid these complications, a treatment schedule aimed at complete destruction of the adrenal cortices and substitution for the induced hypoadrenocorticism was developed [38]. This nonselective destruction has been reported to result in fewer recurrences than does selective destruction [36]. Now o,p'-DDD is no longer used for treatment of PDH, but rather for treatment of inoperable and/or metastasized AT, with the intention of destroying all AT cells, including metastases [39]. In some countries, the use of o,p'-DDD requires specific authorization from the veterinary medicines directorate [12]. It should therefore be used only when trilostane has proved to be ineffective or cannot be used for other reasons, such as when specific side effects or other disorders preclude its use.

A decade ago, trilostane was introduced as a safe and effective alternative to o,p'-DDD in dogs with PDH [40].Trilostane is a competitive inhibitor of $3 \beta$ hydroxysteroid dehydrogenase (HSD3B), an enzyme that is essential in the synthesis of cortisol, aldosterone (ALD), and androstenedione (Figure 4) [12]. In dogs with $\mathrm{PDH}$, treatment with trilostane has the potential to significantly decrease basal and ACTH-stimulated plasma cortisol concentration. This results in loss of negative feedback and thus increased plasma ACTH concentration [41,42]. Consistent with 
its competitive inhibitory effect on HSD3B, trilostane also causes an insignificant decrease in plasma ALD concentration in dogs with PDH, although ALD usually remains within the reference range $[43,44]$. A result, there is a significant increase in plasma renin activity (PRA), which compensates for the decline in ALD. It has been

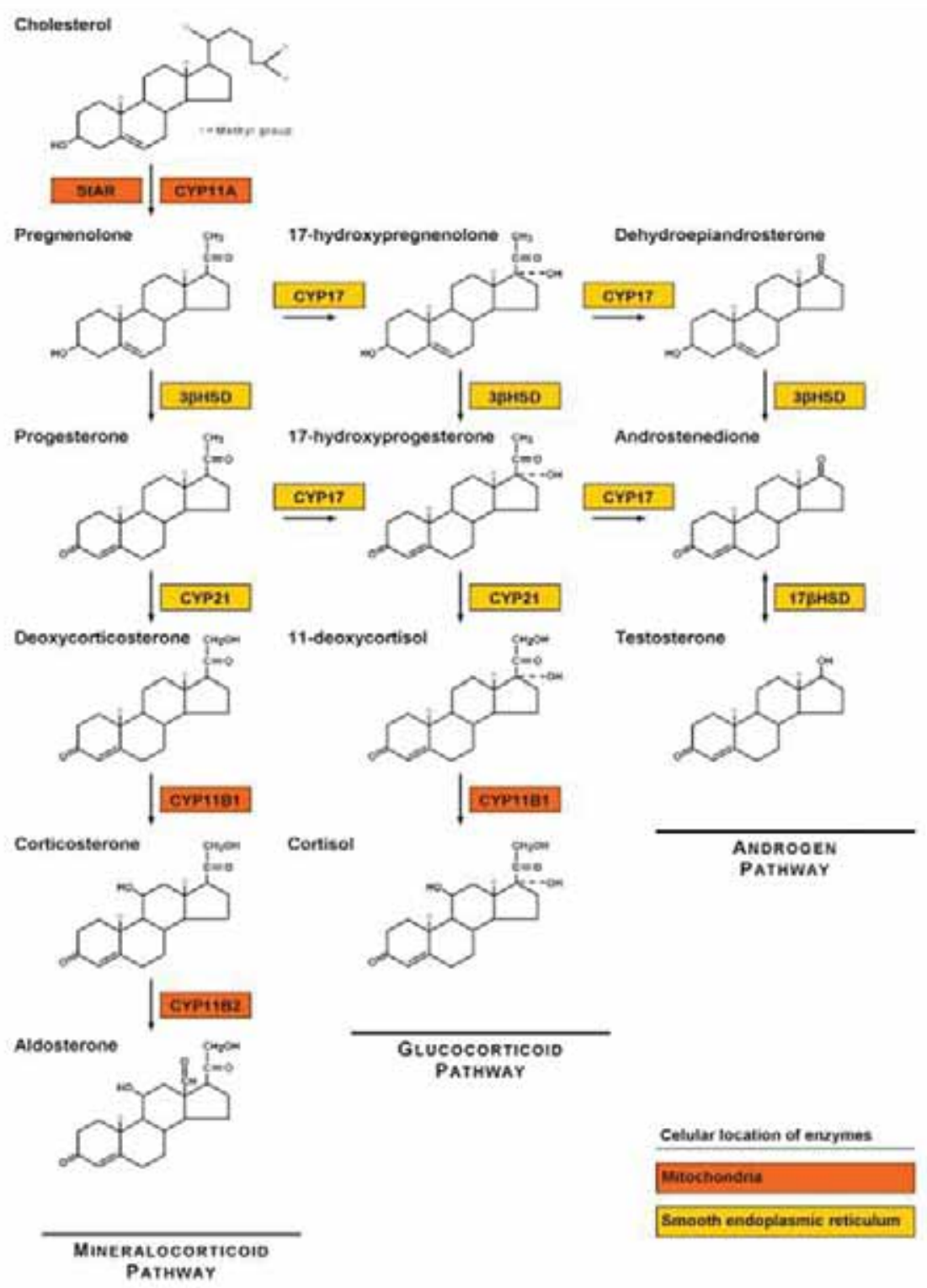

Figure 4. Major pathways of adrenocortical steroid biosynthesisin canine adrenal gland cortex.. StAR $=$ steroidogenic acute regulatory protein, CYP11A $=$ cholesterol side-chain cleavage enzyme, HSD3B2 $=3 \beta$-hydroxysteroid dehydrogenase, $\mathrm{CYP} 17=17 \alpha$-hydroxylase, $\mathrm{CYP} 21=$ 21-hydroxylase, CYP11B1 = 11 $\beta$-hydroxylase, $17 \beta \mathrm{HSD}=17 \beta$-hydroxysteroid dehydrogenaase. Cellular location of enzymes (mitochondria or smooth endoplasmic reticulum) is depicted 
concluded that trilostane not only affects the pituitary-adrenocortical axis but also the renin-ALD axis [42].

Trilostane is absorbed rapidly from the gastrointestinal tract. Administration with food significantly increases the rate and extent of absorption. There is marked variation in the optimal dose and to avoid adverse effects due to overdosage, treatment is started at a relatively low oral dose of $2 \mathrm{mg} / \mathrm{kg}$ body weight once daily [1,12]. This frequency of administration seems to be sufficient to control the clinical signs of hypercortisolism, despite the fact that the effect of trilostane on basal and ACTH-stimulated cortisol is considerably less than 24 hours in most cases [45].

The effectiveness of trilostane therapy is judged by 1) resolution of the clinical signs associated with glucocorticoid excess and 2) the results of an ACTH stimulation test [40]. Within about a week on an appropriate dose of trilostane, there is a clear reduction in polydipsia, polyuria, and polyphagia, although notable improvement in the skin and coat, reduction of central obesity, and increased physical activity requires 3 to 6 months of adequate doses [46]. The purpose of performing an ACTH stimulation test in a dog on trilostane therapy is to determine whether there is sufficient adrenocortical reserve at the time of maximal effect of trilostane, which is about 2-3 hours after administration [45]. Despite its widespread use, the ACTH stimulation test has never been validated for use during trilostane therapy. The author's currently recommended target ranges for the post-ACTH cortisol concentration are presented in Table 1 and are based on the ACTH stimulation test started 2-4 hours after trilostane administration.

Table 1. Adjustments of trilostane dose by ACTH stimulation test performed 2-3 $\mathrm{h}$ after dosing

\begin{tabular}{lcl} 
Clinical manifestation & $\begin{array}{c}\text { Post-ACTH plasma } \\
\text { Cortisol concentration }\end{array}$ & Action \\
\hline $\begin{array}{l}\text { Major clinical signs have } \\
\text { ceased }\end{array}$ & $40-150 \mathrm{nmol} / 1$ & The dose is left unchanged \\
$\begin{array}{l}\text { Clinical signs of } \\
\text { hypercortisolism have not } \\
\text { decreased or ceased }\end{array}$ & $40-150 \mathrm{nmol} / 1$ & $\begin{array}{l}\text { Slightly increase the dose or rather divide } \\
\text { in two portions }\end{array}$ \\
$\begin{array}{l}\text { No effect in clinical signs } \\
\text { Major clinical signs have } \\
\text { ceased }\end{array}$ & $>150 \mathrm{nmol} / 1$ & $\begin{array}{l}\text { Increase the daily dose by } 1 \mathrm{mg} / \mathrm{kg} \\
\text { Do not change the dose, but monitor the } \\
\text { dog closely for the recurrence of signs of } \\
\text { hypercortisolism }\end{array}$ \\
$\begin{array}{l}\text { Major clinical signs have } \\
\text { ceased and the dog is in } \\
\text { good clinical condition }\end{array}$ & $<40 \mathrm{nmol} / 1$ & $\begin{array}{l}\text { Trilostane dosage is decreased by } 50 \% \text { and } \\
\text { the dog is monitored closely for signs of } \\
\text { hypocortisolism }\end{array}$ \\
$\begin{array}{l}\text { Sings suggested } \\
\text { of adrenocortical } \\
\text { insufficiency, such as } \\
\text { lethargy and anorexia }\end{array}$ & $<40 \mathrm{nmol} / 1$ & $\begin{array}{l}\text { Stop the treatment and administer } \\
\text { intravenous fluids and glucocorticoids }\end{array}$ \\
\hline
\end{tabular}


Trilostane is generally well tolerated at the recommended dose and with appropriate monitoring. Overdosage results in cortisol deficiency and sometimes even mineralocorticoid deficiency $[47,48]$. The most common clinical signs are inappetence, weakness, diarrhea, weight loss, and abdominal pain. If they appear, trilostane must be stopped immediately. Recovery is usually rapid but trilostane will still be required to control the clinical signs of hypercortisolism [42]. Hence the dose is reduced by $50 \%$ and monitoring is continued.

Another-but life-threatening-side effect of trilostane is adrenocortical necrosis [47]. Its etiology is uncertain but thought to be related to increased basal ACTH concentration [49]. Trilostane therapy causes basal ACTH concentration to increase as a physiologic reaction to the lowering of the plasma cortisol concentration [42]. This in turn leads to the increase in size of the adrenal glands that is observed in many dogs treated with trilostane. Paradoxically, even short periods of highly elevated ACTH levels can result in focal necrosis and hemorrhage in the adrenal glands in humans. Presumably, elevated ACTH levels in dogs with PDH could also lead eventually to adrenocortical necrosis [42]. There have been several case reports of dogs with adrenal necrosis in which the severity of the lesions may have been related to the high doses of trilostane used and the long duration of treatment $[47,48]$. Dogs with suspected adrenocortical necrosis are presented as emergencies and deserve prompt corticosteroid substitution and supportive therapy with fluid, an antiemetic, and an analgesic. Usually, glucocorticoid supplementation must be continued after the dog is discharged.

ACTH concentration also increases in normal dogs treated with trilostane. This is associated with an increase in pituitary size (as assessed by MRI) and histological evidence of pituitary corticotroph hyperplasia and bilateral adrenocortical hyperplasia [50]. It seems reasonable to assume that trilostane could result in an increase in size of pituitary tumors, but no evidence for this has been reported. Nevertheless, at this institution a control CT scan is obtained 12 months after initiation of therapy when trilostane is used in a dog with a pituitary microadenoma. This objective evaluation of the size of the pituitary tumor enables surgical intervention to be undertaken in time, if needed.

In order to diminish the likelihood of side effects and possibly improve effectiveness, the use of a lower dose of trilostane and twice-daily administration has been introduced. There have been two reports of a better clinical response to twice daily administration, with no difference in adverse effects [51,52].

In most veterinary institutions trilostane administration is started once daily, the main considerations being the relatively high cost of the drug and owner compliance. The administration is increased to twice daily if the clinical response is unsatisfactory and an ACTH stimulation test reveals mild adrenocortical reserve. Whether the drug should be administered once or twice daily is still uncertain. Long-term studies using even very low doses have demonstrated good clinical responses [53,54]. 
In dogs with hypercortisolism and concurrent diabetes mellitus (DM), trilostane should be administered at the same time as insulin. Hence, in most diabetics it is started twice daily [12]. It has been suggested that twice-daily administration of trilostane might also be beneficial in dogs with hypercortisolism and severe proteinuria, but this has not been investigated.

The median survival time for dogs with PDH treated with trilostane once daily (662 days), is similar to that for dogs with PDH undergoing selective adrenocorticolysis with o,p'-DDD (798 days) [55]. The median survival time for dogs with PDH treated with trilostane twice daily (900 days) is comparable to that for dogs with PDH undergoing nonselective adrenocorticolysis with o,p'-DDD (720 days) [56]. In these studies no attempt was made to relate the size of the pituitary tumor to the survival time.

\section{Pituitary inadiation therapy}

Radiation therapy is considered to be the treatment of choice for pituitary macrotumors with suprasellar extension. Megavoltage irradiation from a lineal accelerator or cobalt 60 source is required to penetrate to the depth of the pituitary without injuring overlying soft tissues [57-59]. Radiotherapy is effective in reducing the size of such pituitary tumors, but with a quite variable delay, from 1 to 16 months. The reduction in size is gradual in onset but can continue for a year or more after completion of the therapy [59]. The improvement in clinical signs of hypercortisolism is associated with reduced pituitary ACTH secretion and may not be evident until a few months after therapy. Hence, treatment with trilostane is advocated until this occurs.

Radiotherapy is only available in a few veterinary institutions. Most treatment protocols involve irradiation for 4 weeks on alternate days and since anesthesia is required, the anesthetic risk must be evaluated carefully before recommending this approach $[58,59]$. Data on the efficacy of pituitary irradiation in veterinary medicine are scarce. The best results are to be expected in dogs with pituitary macrotumors without neurological signs. If neurological signs are present, they may increase with the gradual decrease in pituitary size after radiotherapy, and this is usually decisive for euthanasia. Kent et al. [60], reported a significant correlation between the relative size of the tumor and the severity of neurological signs and between the relative size of the tumor and remission of neurological signs.

\section{Adrenal-dependent hypercortisolism}

\section{Surgery}

The treatment of choice for unilateral ACT is adrenalectomy, because successful removal eliminates both the tumor and the associated clinical signs of glucocorticoid excess, without the need for lifelong medication. Because of the atrophy of the cortex of the nontumorous contralateral adrenal gland, due to the longstanding glucocorticoid excess, glucocorticoid substitution is needed temporarily [1]. Substitution is started at 
the time of anesthesia and is continued for 6 to 8 weeks after surgery. The dose of glucocorticoid is decreased gradually to facilitate progressively increasing feedback stimulation of pituitary ACTH secretion.

Adrenalectomy can be performed in dogs via a ventral midline celiotomy, with paracostal extension of the incision when needed, or via a paracostal approach [6163]. The choice remains controversial. While the midline approach allows complete exploration of the abdomen and direct examination of both adrenal glands, the paracostal approach affords better surgical access to the ipsilateral adrenal with less trauma to the liver, pancreas, and spleen, and less risk of wound dehiscence.

Regardless of the surgical approach, adrenalectomy has a perioperative mortality of about $20 \%[62,64]$. This is explained in part by the relatively high risk of postoperative complications such as renal failure, pneumonia, pancreatitis, and pulmonary thromboembolism, but it also reflects the difficulty of the surgical procedure per se. In dogs with hypercortisolism access to the adrenals is usually hindered by central obesity and hepatomegaly. Furthermore, ATs are friable, lie in close proximity to the vena cava, and tend to invade blood vessels. As for hypophysectomy [35], the skill of the surgeon and of the rest of the team affects the outcome. Postoperative intensive care facilities are essential and hence surgery should be undertaken only in referral centers. At some institutions, treatment with trilostane prior to surgery is advocated, but it is not known whether this improves survival.

In the recent years, laparoscopic adrenalectomy has gained in popularity $[65,66]$. Its potential advantages over open techniques include reduced manipulation of other abdominal organs, an excellent view of abdominal structures, decreased surgical wound complications, and improved postoperative comfort. While ATs up to $5 \mathrm{~cm}$ in diameter do not pose a problem for laparoscopic removal, if ingrowth in the blood vessels is suspected, the open technique is preferred. Pelaes et al. (2008) reported creating a small window in the adrenal capsule to aspirate necrotic content and thus reduce the risk of rupture of the AT and escape of neoplastic cells during surgery [65]. Although the clinical consequences of capsule rupture and leakage of AT cells remain unclear, it is probably better to avoid this complication by delicate dissection, initial sealing, and perhaps the use of a retrieval bag [66].

The median survival time after adrenalectomy is about 2 years, although some dogs survive more than 4 years [64].

\section{Medical treatment}

The adrenocorticolytic drug mitotane (o,p'-DDD) has been the mainstay of medical treatment for inoperable ACTs and/or metastases. While cortisol excess can be treated successfully by selective destruction of the adrenal cortex, the aim of mitotane therapy in cortisol-secreting ATs is complete destruction of the adrenocortical tumor tissue [1]. Mitotane is administered in a dose of $50-75 \mathrm{mg} / \mathrm{kg}$ body weight per day. It is given daily for the first 5 days, then on alternate days for an additional 20 days. Substitution 
with cortisone acetate, fludrocortisone acetate, and salt is started on the third day. The dose of cortisone begins at twice the usual replacement dose and is reduced to 0.5 to $1 \mathrm{mg} / \mathrm{kg}$ per day at the end of the 25 days of mitotane therapy. The doses of fludrocortisone $(0.0125-0025 \mathrm{mg} / \mathrm{kg}$ per day) and salt $(0.1 \mathrm{mg} / \mathrm{kg}$ per day) are adjusted by measurements of plasma sodium and potassium concentrations. After the 25 days of mitotane administration, the magnitude of destruction of the AT is evaluated by measurement of the UCCR. The evening doses cortisone and fludrocortisone are omitted prior to the morning urine collection for the UCCR. Complete destruction of the AT results in a very low UCCR. In order to prevent recurrence, mitotane is administered once weekly for at least 6 months, or even lifelong.

The chemotherapy with mitotane produces side effects, such as vomiting, poor appetite or anorexia, and sometimes ataxia [39]. The owner is instructed to stop giving mitotane if any of these occur, but to continue the substitution therapy. If for any reason the dog cannot take or retain the tablets two times in succession, injectable medications should be started. If side effects are ignored and the substitution therapy is refused, the dog can develop a hypoadrenocorticoid (Addisonian) crisis. Owner compliance is essential for successful chemotherapy with mitotane. The injectable glucocorticoid and mineralocorticoid are provided to the owner for use if necessary [36].

If there is metastasis of a functional AT or if neither adrenalectomy nor adrenocortical destruction with mitotane is an option, trilostane therapy can be used as a palliative treatment $[67,68]$. Although the manufacturer's recommended dose of trilostane does not differentiate between treatment of pituitary and adrenal hypercortisolism, experience has shown that ATs are more sensitive to trilostane than are hyperplastic adrenal glands. At this institution, the starting dose of trilostane used in dogs with AT is $1 \mathrm{mg} / \mathrm{kg}$ body weight is. Monitoring of trilostane therapy consist of evaluation of clinical signs and the ACTH stimulation test, as in trilostane therapy for PHD $[1,12]$.

The median survival time in dogs with ATs treated with mitotane were 10 and 15.6 months and in those treated with trilostane it was 14 months [69,70]. In both studies mitotane was used in a protocol for selective destruction to resolve the clinical signs and not for complete destruction of the AT and metastases. It is thus not surprising that the survival times for mitotane and trilostane were similar. However, in both studies survival of animals with metastases was significantly shorter than in those without. This supports the use of the protocol to attempt complete destruction with mitotane and continuing weekly administration.

\section{CONCLUSION}

Both pituitary-dependent and adrenal-dependent hypercortisolism can be treated either surgically or medically and pituitary macrotumors can be treated by radiotherapy. In order to determine the best treatment, factors such as the patient's age, concurrent diseases, and general health should be considered. Diagnostic imaging is very helpful in 
the process of decision making. Dogs with PHD caused by a pituitary microadenoma can be treated with the adrenocorticostatic drug trilostane. Hypophysectomy is not necessary, since the main problem is cortisol excess and not a pituitary mass. In young dogs with hypercortisolism a pituitary scan is recommended after 12 months of trilostane administration, to evaluate the size of the pituitary and determine whether surgical intervention is needed. In dogs with an enlarged pituitary, medical treatment will control the clinical signs of hypercortisolism, but not the growth of the tumor, and therefore hypophysectomy is preferred. Lifelong substitution with cortisone and thyroxine will be required. Pituitary macrotumors can be managed surgically by debulking or by radiotherapy.

Because unilateral ATs can be malignant, adrenalectomy is the best treatment option. Administration of cortisone acetate is required following surgery, because the contralateral adrenal cortex is atrophic as a result of feedback suppression of pituitary ACTH secretion, but this is reversed within two months. Adrenalectomy, like hypophysectomy, requires special facilities and a team consisting of an experienced surgeon, endocrinologist, radiologist, anesthesiologist, and critical care specialist.

The medical treatment of hypercortisolism aims at the suppression of cortisol secretion and control of the clinical signs. Trilostane has become the most commonly used drug. It has been shown to be safe and effective, but its dosage needs to be controlled on a regular basis and its long-term effects are not yet known. The major indication for medical treatment with trilostane is PDH, but it can also be used in adrenal-dependent hypercortisolism when surgery is not possible due to the presence of metastasis or for other reasons. Mitotane is still available for use in dogs with inoperable, cortisol-secreting AT. A complete destruction protocol is used for this purpose and may be followed by once-weekly administration in order to suppress the growth of the AT.

\section{REFERENCES}

1. Galac S, Reusch C, Kooistra H, Rijnberk A. Adrenals. In: Clinical E ndocrinology of D ogs and Cats. Hannover, Germany:Schlutersche; 2010, 93-154.

2. Galac S, Kars VJ, Voorhout G, Mol JA, Kooistra HS. ACTH-independent hyperadrenocorticism due to food-dependent hypercortisolemia in a dog: A case report. Vet J 2008,177:141-143.

3. Galac S, Kooistra HS, Voorhout G, van den Ingh TS, Mol JA, van den Berg G, Meij BP. Hyperadrenocorticism in a dog due to ectopic secretion of adrenocorticotropic hormone. Domest Anim Endocrinol 2005,28:338-348.

4. Boujon, CE. Ritz, U. Rossi, GL. Bestetti, GE. A clinic-pathological study of canine Cushing`s disease caused by pituitary carcinoma. J Comp Path 1991,105:353-365.

5. Labelle P, Kyles E, Farver TB, de Cock HEV. Indicators of malignancy of canine adrenocortical tumors: Histopathology and proliferation index. Vet Pathol 2004,41:490497.

6. Kooistra HS, Galac S. Recent advances in the diagnosis of cushing's syndrome in dogs. Vet Clin North Am Small Anim Pract 2010,40:259-267. 
7. Behrend EN, Kooistra HS, Nelson R, Reusch CE, Scott-Moncrieff JC. Diagnosis of spontaneous canine hyperadrenocorticism: 2012 ACVIM consensus statement (small animal]. J Vet Intern Med 2013,27:1292-1304.

8. Gilor C, Graves TK. Interpretation of laboratory tests for canine cushing's syndrome. Top Companion Anim Med. 2011,26:98-108.

9. van Vonderen IK, Kooistra HS, Rijnberk A. Influence of veterinary care on the urinary corticoid:Creatinine ratio in dogs. J Vet Intern Med 1998,12:431-435.

10. Galac S, Buijtels JJ, Kooistra HS. Urinary corticoid: Creatinine ratios in dogs with pituitarydependent hypercortisolism during trilostane treatment. J Vet Intern Med 2009,23:12141219.

11. Kintzer PP, Peterson ME. Primary and secondary canine hypoadrenocorticism. Vet Clin North Am Small Anim Pract 1997,27:349-357.

12. Ramsey IK. Trilostane in dogs. Vet Clin North Am Small Anim Pract 2010,40:269-283.

13. Auriemma E, Barthez PY, van der Vlugt-Meijer RH, Voorhout G, Meij BP. Computed tomography and low-field magnetic resonance imaging of the pituitary gland in dogs with pituitary-dependent hyperadrenocorticism: 11 cases (2001-2003). J Am Vet Med Assoc 2009,15:409-414.

14. van der Vlugt-Meijer RH, Meij BP, Voorhout G. Intraobserver and interobserver agreement, reproducibility, and accuracy of computed tomographic measurements of pituitary gland dimensions in healthy dogs. Am J Vet Res 2006,67:1750-1755.

15. van der Vlugt-Meijer RH, Meij BP, Voorhout G. Dynamic computed tomographic evaluation of the pituitary gland in healthy dogs. Am J Vet Res 2004,65:1518-1524.

16. Kooistra HS, Voorhout G, Mol JA, Rijnberk A. Correlation between impairment of glucocorticoid feedback and the size of the pituitary gland in dogs with pituitary-dependent hyperadrenocorticism. J Endocrinol 1997,152:387-394.

17. van der Vlugt-Meijer RH, Meij BP, van den Ingh TS, Rijnberk A, Voorhout G. Dynamic computed tomography of the pituitary gland in dogs with pituitary-dependent hyperadrenocorticism. J Vet Intern Med 2003,17:773-780.

18. van der Vlugt-Meijer RH, Meij BP, Voorhout G. Thin-slice three-dimensional gradientecho magnetic resonance imaging of the pituitary gland in healthy dogs. Am J Vet Res 2006,67:1865-1872.

19. Rodriguez Pineiro MI, de Fornel-Thibaud P, Benchekroun G, Garnier F, Maurey-Guenec C, Delisle $\mathrm{F}$, et al. Use of computed tomography adrenal gland measurement for differentiating ACTH dependence from ACTH independence in 64 dogs with hyperadenocorticism. J Vet Intern Med 2011,25:1066-1074.

20. Bertolini G, Furlanello T, De Lorenzi D, Caldin M. Computed tomographic quantification of canine adrenal gland volume and attenuation. Vet Radiol Ultrasound 2006,47:444-448.

21. Bertolini G, Furlanello T, Drigo M, Caldin M. Computed tomographic adrenal gland quantification in canine adrenocorticotroph hormone-dependent hyperadrenocorticism. Vet Radiol Ultrasound 2008,49:449-453.

22. Mogicato G, Layssol-Lamour C, Conchou F, Diquelou A, Raharison F, Sautet J, Concordet D. Ultrasonographic evaluation of the adrenal glands in healthy dogs: Repeatability, reproducibility, observer-dependent variability, and the effect of bodyweight, age and sex. Vet Rec 2011,168:130-134.

23. Barthez PY, Nyland TG, Feldman EC. Ultrasonographic evaluation of the adrenal glands in dogs. J Am Vet Med Assoc 1995,1:1180-1183. 
24. Choi J, Kim H, Yoon J. Ultrasonographic adrenal gland measurements in clinically normal small breed dogs and comparison with pituitary-dependent hyperadrenocorticism. J Vet Med Sci. 2011,73:985-959.

25. Benchekroun G, de Fornel-Thibaud P, Rodriguez Pineiro MI, Rault D, Besso J, Cohen A, et al. Ultrasonography criteria for differentiating ACTH dependency from ACTH independency in 47 dogs with hyperadrenocorticism and equivocal adrenal asymmetry. J Vet Intern Med2010,24:1077-1085.

26. Pey P, Vignoli M, Haers H, Duchateau L, Rossi F, Saunders JH. Contrast-enhanced ultrasonography of the normal canine adrenal gland. Vet Radiol Ultrasound. 2011,52:560567.

27. Pey P, Rossi F, Vignoli M, Duchateau L, Marescaux L, Saunders JH. Use of contrastenhanced ultrasonography to characterize adrenal gland tumors in dogs. Am J Vet Res 2014, 75:886-892.

28. Bargellini P, Orlandi R, Paloni C, Rubini G, Fonti P, Peterson ME, Boiti C. Contrastenhanced ultrasonographic characteristics of adrenal glands in dogs with pituitarydependent hyperadrenocorticism. Vet Radiol Ultrasound 2013,54:283-292.

29. Greco DS, Peterson ME, Davidson AP, Feldman EC, Komurek K. Concurrent pituitary and adrenal tumors in dogs with hyperadrenocorticism: 17 cases (1978-1995). J Am Vet Med Assoc 1999,214:1349-1353.

30. Thuroczy J, van Sluijs FJ, Kooistra HS, Voorhout G, Mol JA, van der Linde-Sipman JS, Rijnberk A. Multiple endocrine neoplasias in a dog: Corticotrophic tumour, bilateral adrenocortical tumours, and pheochromocytoma. Vet Q 1998,20:56-61.

31. Meij BP, Voorhout G, van den Ingh TS, Hazewinkel HA, Teske E, Rijnberk A. Results of transsphenoidal hypophysectomy in 52 dogs with pituitary-dependent hyperadrenocorticism. Vet Surg 1998,27:246-261.

32. Hanson JM, van 't HM, Voorhout G, Teske E, Kooistra HS, Meij BP. Efficacy of transsphenoidal hypophysectomy in treatment of dogs with pituitary-dependent hyperadrenocorticism. J Vet Intern Med 2005,19:687-694.

33. Hanson JM, Teske E, Voorhout G, Galac S, Kooistra HS, Meij BP. Prognostic factors for outcome after transsphenoidal hypophysectomy in dogs with pituitary-dependent hyperadrenocorticism. J Neurosurg 2007,107:830-840.

34. Meij BP, Mol JA, van den Ingh TS, Bevers MM, Hazewinkel HA, Rijnberk A. Assessment of pituitary function after transsphenoidal hypophysectomy in beagle dogs. Domest Anim Endocrinol 1997, 14:81-97.

35. Meij BP. Hypophysectomy as a treatment for canine and feline Cushing's disease. Vet Clin North Am Small Anim Pract 2001, 31:1015-1041.

36. den Hertog E, Braakman JC, Teske E, Kooistra HS, Rijnberk A. Results of non-selective adrenocorticolysis by o,p'-DDD in 129 dogs with pituitary-dependent hyperadrenocorticism. Vet Rec 1999,144:12-17.

37. Peterson ME, Kintzer PP. Medical treatment of pituitary-dependent hyperadrenocorticism. mitotane. Vet Clin North Am Small Anim Pract 1997,27:255-272.

38. Rijnberk A, Belshaw BE. An alternative protocol for the medical management of canine pituitary-dependent hyperadrenocorticism. Vet Rec 1988,122:486-488.

39. Kintzer PP, Peterson ME. Diagnosis and management of canine cortisol-secreting adrenal tumors. Vet Clin North Am Small Anim Pract 1997,27:299-307. 
40. Neiger R, Ramsey I, O’Connor J, Hurley KJ, Mooney CT. Trilostane treatment of 78 dogs with pituitary-dependent hyperadrenocorticism. Vet Rec 2002,150:799-804.

41. Witt AL, Neiger R. Adrenocorticotropic hormone levels in dogs with pituitary-dependent hyperadrenocorticism following trilostane therapy. Vet Rec 2004,154:399-400.

42. Galac S, Buijtels JJ, Mol JA, Kooistra HS. Effects of trilostane on the pituitary-adrenocortical and renin-aldosterone axis in dogs with pituitary-dependent hypercortisolism. Vet J 2010,183:75-80.

43. Sieber-Ruckstuhl NS, Boretti FS, Wenger M, Maser-Gluth C, Reusch CE. Serum concentrations of cortisol and cortisone in healthy dogs and dogs with pituitary-dependent hyperadrenocorticism treated with trilostane. Vet Rec 2008,163:477-481.

44. Wenger M, Sieber-Ruckstuhl NS, Muller C, Reusch CE. Effect of trilostane on serum concentrations of aldosterone, cortisol, and potassium in dogs with pituitary-dependent hyperadrenocorticism. Am J Vet Res 2004,65:1245-1250.

45. Griebsch C, Lehnert C, Williams GJ, Failing K, Neiger R. Effect of trilostane on hormone and serum electrolyte concentrations in dogs with pituitary-dependent hyperadrenocorticism. J Vet Intern Med 2014,28:160-165.

46. Ruckstuhl NS, Nett CS, Reusch CE. Results of clinical examinations, laboratory tests, and ultrasonography in dogs with pituitary-dependent hyperadrenocorticism treated with trilostane. Am J Vet Res 2002,63:506-512.

47. Chapman PS, Kelly DF, Archer J, Brockman DJ, Neiger R. Adrenal necrosis in a dog receiving trilostane for the treatment of hyperadrenocorticism. J Small Anim Pract 2004, 45:307-310.

48. Ramsey IK, Richardson J, Lenard Z, Tebb AJ, Irwin PJ. Persistent isolated hypocortisolism following brief treatment with trilostane. Aust Vet J 2008,86:491-495.

49. Burkhardt WA, Guscetti F, Boretti FS, Ivos Todesco A, Aldajarov N, Lutz TA, Reusch CE, Siber-Ruckstuhl NS. Adrenocorticotropic hormone, but not trilostane, causes severe adrenal hemorrhage, vacuolization, and apoptosis in rats. Domest Anim Endocrinol 2011,40:155-164.

50. Teshima T, Matsumoto H, Kumagai T, Kurano M, Koyama H. Expression of 11betahydroxysteroid dehydrogenase isoforms in canine adrenal glands treated with trilostane. Vet J 2014,200:452-455.

51. Arenas C, Melian C, Perez-Alenza MD. Evaluation of 2 trilostane protocols for the treatment of canine pituitary-dependent hyperadrenocorticism: Twice daily versus once daily. J Vet Intern Med 2013,27:1478-1485.

52. Augusto M, Burden A, Neiger R, Ramsey IK. A comparison of once and twice daily administration of trilostane to dogs with hyperadrenocorticism. Tierarztl Prax Ausg Kleintiere Heimtiere 2012,40:415-424.

53. Vaughan MA, Feldman EC, Hoar BR, Nelson RW. Evaluation of twice-daily, lowdose trilostane treatment administered orally in dogs with naturally occurring hyperadrenocorticism. J Am Vet Med Assoc 2008,232:1321-1328.

54. Feldman EC. Evaluation of twice-daily lower-dose trilostane treatment administered orally in dogs with naturally occurring hyperadrenocorticism. J Am Vet Med Assoc 2011,238:14411451.

55. Barker EN, Campbell S, Tebb AJ, Neiger R, Herrtage ME, Reid SW, Ramsey IK. A comparison of the survival times of dogs treated with mitotane or trilostane for pituitarydependent hyperadrenocorticism. J Vet Intern Med 2005,19:810-815. 
56. Clemente M, De Andres PJ, Arenas C, Melian C, Morales M, Perez-Alenza MD. Comparison of non-selective adrenocorticolysis with mitotane or trilostane for the treatment of dogs with pituitary-dependent hyperadrenocorticism. Vet Rec 2007,161:805-809.

57. Theon AP, Feldman EC. Megavoltage irradiation of pituitary macrotumors in dogs with neurologic signs. J Am Vet Med Assoc 1998,213:225-231.

58. Goossens MM, Feldman EC, Theon AP, Koblik PD. Efficacy of cobalt 60 radiotherapy in dogs with pituitary-dependent hyperadrenocorticism. J Am Vet Med Assoc 1998,212:374376.

59. de Fornel P, Delisle F, Devauchelle P, Rosenberg D. Effects of radiotherapy on pituitary corticotroph macrotumors in dogs: A retrospective study of 12 cases. Can Vet J 2007, 48:481-486.

60. Kent MS, Bommarito D, Feldman E, Theon AP. Survival, neurologic response, and prognostic factors in dogs with pituitary masses treated with radiation therapy and untreated dogs. J Vet Intern Med 2007,21:1027-1033.

61. Massari F, Nicoli S, Romanelli G, Buracco P, Zini E. Adrenalectomy in dogs with adrenal gland tumors: 52 cases (2002-2008). J Am Vet Med Assoc 2011,239:216-221.

62. Schwartz P, Kovak JR, Koprowski A, Ludwig LL, Monette S, Bergman PJ. Evaluation of prognostic factors in the surgical treatment of adrenal gland tumors in dogs: 41 cases (1999-2005). J Am Vet Med Assoc 2008,232:77-84.

63. Kyles AE, Feldman EC, De Cock HE, Kass PH, Mathews KG, Hardie EM, et al. Surgical management of adrenal gland tumors with and without associated tumor thrombi in dogs: 40 cases (1994-2001). J Am Vet Med Assoc 2003,223:654-662.

64. van Sluijs FJ, Sjollema BE, Voorhout G, van den Ingh TS, Rijnberk A. Results of adrenalectomy in 36 dogs with hyperadrenocorticism caused by adreno-cortical tumour. Vet Q. 1995,17:113-116.

65. Jimenez Pelaez M, Bouvy BM, Dupre GP. Laparoscopic adrenalectomy for treatment of unilateral adrenocortical carcinomas: Technique, complications, and results in seven dogs. Vet Surg 2008,37:444-453.

66. Naan EC, Kirpensteijn J, Dupre GP, Galac S, Radlinsky MG. Innovative approach to laparoscopic adrenalectomy for treatment of unilateral adrenal gland tumors in dogs. Vet Surg. 2013,6:710-715.

67. Eastwood JM, Elwood CM, Hurley KJ. Trilostane treatment of a dog with functional adrenocortical neoplasia. J Small Anim Pract 2003,44:126-131.

68. Benchekroun G, de Fornel-Thibaud P, Lafarge S, Gomez E, Begon D, Delisle F, Moraillon R, Heripret D, Maurey C, Rosenberg D. Trilostane therapy for hyperadrenocorticism in three dogs with adrenocortical metastasis. Vet Rec 2008,163:190-192.

69. Helm JR, McLauchlan G, Boden LA, Frowde PE, Collings AJ, Tebb AJ, Elwood CM, Herrtage ME, Parkin TD, Ramsey IK. A comparison of factors that influence survival in dogs with adrenal-dependent hyperadrenocorticism treated with mitotane or trilostane. J Vet Intern Med 2011,25:251-60.

70. Arenas C, Perez-Alenza D, Melian C. Clinical features, outcome and prognostic factors in dogs diagnosed with non-cortisol-secreting adrenal tumours without adrenalectomy: 20 cases (1994-2009]. Vet Rec2013,173:501-504. 


\title{
IZBOR NAJBOLJE TERAPIJE KOD CUSHING-OVOG SINDROMA PASA
}

\author{
GALAC Sara
}

Spontani hiperkorticizam (Cushingov sindrom) je česta endokrinopatija kod pasa. Hiperkorticizam zavisan kako od funkcije nadbubrežne žlezde tako i od funkcije hipofize, zahteva specifičnu terapiju, pri čemu je imidžing dijagnostika veoma korisna za izbor pravilne terapije. Da bi se izbegli nesporazumi, ciljevi i očekivanja tretmana treba da se uspostave i prodiskutuju sa vlasnikom pre primene terapije. Klinički simptomi hipofiza zavisnog hiperkorticizma koji je posledica mikroadenoma hipofize, mogu se kontrolisati adrenokortikosteroidom trilostanom. Međutim, ovaj lek neće uticati na sam tumor. Iz tog razloga preporučuje se hipofizektomija kod pasa kod kojih je uvećana hipofiza, a koji su u dobrom zdravstvenom stanju i kod kojih se očekuje da požive duži vremenski period. Neoperativni tumori hipofize mogu da se tretiraju radioterapijom. Najbolja terapija pasa sa adrenokortikalnim tumorima koji utiču na sekreciju kortizola, sastoji se iz adrenalektomije. U slučaju da hirurški zahvat nije moguć ukoliko je tumor zahvatio krvne sudove ili zbog metastatskog širenja tumora, preporučuje se primena mitotana. Treba uzeti u obzir terapiju trilostanom,ali se u ovom slučaju radi samo o palijativnoj terapiji: nema uticaja na adrenokortikalni tumor. 